\title{
IgG subclasses in smokers with chronic bronchitis and recurrent exacerbations
}

\author{
I Qvarfordt, G C Riise, B A Andersson, S Larsson
}

\begin{abstract}
Background-Tobacco smokers have lower serum levels of IgG than nonsmokers. IgG subclass deficiency is common in patients with recurrent respiratory infections. Recurrent bronchial infections are common in smokers with chronic bronchitis (CB). We have investigated whether susceptibility to recurrent exacerbations in smokers with $\mathrm{CB}$ is associated with altered IgG subclass levels or IgG subclass deficiency.

Methods-Serum levels of IgG, IgA, IgM, and IgG subclasses 1-4 were determined by radial immunodiffusion in 100 subjects: 33 smokers with stable $C B$ and recurrent exacerbations, 24 asymptomatic smokers, and 43 healthy never smokers. Systemic tobacco exposure was verified and excluded using a serum cotinine ELISA. Immunoglobulin data were log transformed to enable use of parametric statistical methods.
\end{abstract}

Results-Compared with never smokers, both patients with $C B$ and asymptomatic smokers had significantly lower levels of IgG (median $9.7 \mathrm{~g} / 1$ (range 5.6-15.2) and $9.9(6.1-12.1) \mathrm{g} / 1 v 12.0(6.9-18.5) \mathrm{g} / \mathrm{l})$ and IgG2 (2.8 (0.9-5.9) g/1 and $2.5(1.0-6.3) \mathrm{g} / 1$ $v 4.0(1.7-10.2) \mathrm{g} / 1)$. The estimated ratio of median values between the patients with $\mathrm{CB}$ and never smokers was 0.78 (95\% confidence interval (CI) 0.69 to $\mathbf{0 . 8 9}$ ) for IgG and $0.65(95 \%$ CI 0.50 to 0.83$)$ for IgG2. The corresponding ratios between asymptomatic smokers and never smokers were $0.79(95 \% \mathrm{CI} 0.69$ to 0.91$)$ and 0.60 (95\% CI 0.50 to 0.83 ), respectively. There were no significant differences between the smoking groups.

Conclusions-Susceptibility to recurrent exacerbations in smokers with $\mathrm{CB}$ is not associated with lower levels of IgG subclasses than can be accounted for by smoking per se.

(Thorax 2001;56:445-449)

Keywords: chronic bronchitis; IgG subclasses; recurrent exacerbations; tobacco smoking

Concentrations of immunoglobulins (Ig) in serum are affected by tobacco smoking. A series of large studies have shown lower serum levels of IgG in smokers than in nonsmokers, ${ }^{1-4}$ and in several the levels of IgA were also significantly lower. ${ }^{13}$

In tobacco smokers bronchial infections are common $^{5}$ and seem to be related to the presence of chronic bronchitis (CB). ${ }^{6}$ These infections mostly appear in the form of recurrent acute exacerbations characterised by increased sputum volume and purulence, cough, and breathing difficulties. ${ }^{7}$ Whether smoking induced alterations in serum Ig levels are important for the susceptibility to recurrent exacerbations in patients with $\mathrm{CB}$ is not known. In previous studies of smokers with $\mathrm{CB}$ we have found significantly lower levels of IgG1 and IgG2 than in healthy never smokers. ${ }^{8}$ However, when asymptomatic smokers and smokers with $\mathrm{CB}$ and recurrent exacerbations were compared in a later study, the only difference between the groups was a slightly lower level of IgG3 in the patient group. ${ }^{9}$ No other studies addressing this issue with a relevant control group have been undertaken.

The aim of the present study was therefore to investigate the hypothesis that susceptibility to respiratory infections in smokers with $\mathrm{CB}$ is associated with lower levels of $\operatorname{IgG}$ and $\operatorname{IgG}$ subclasses or a higher frequency of IgG subclass deficiency than can be accounted for by smoking per se.

\section{Methods}

STUDY DESIGN

The study was a cross sectional investigation of serum Ig and IgG subclass levels in three well defined subjects groups: smokers with $\mathrm{CB}$ and recurrent exacerbations, asymptomatic smokers, and never smokers. The subjects were recruited from patient files at the department of respiratory medicine and by advertisement in a daily newspaper. The study was performed at the Sahlgrenska University Hospital, Göteborg, a tertiary teaching hospital, and was approved by the ethics committee at Göteborg University.

\section{STUDY POPULATION}

Patients with symptoms of $\mathrm{CB}$, as defined by the American Thoracic Society (ATS), ${ }^{10}$ were studied. Coexisting chronic airway obstruction, defined as forced expiratory volume in one second $\left(\mathrm{FEV}_{1}\right)$ of $<80 \%$ of predicted normal, was allowed. All were current smokers, having smoked at least 10 cigarettes per day for more than 10 years. In addition, all had a history of two or more acute exacerbations during the past 12 months as defined by Boman et $a .^{7}$ The total number of exacerbations during the past 2 years was recorded.

For comparison, two control groups were studied. The first comprised asymptomatic smokers, all of whom were current smokers who had smoked at least 10 cigarettes per day for more than 10 years without fulfilling the ATS criteria for CB. ${ }^{10}$ They had normal ventilatory lung function, defined as $\mathrm{FEV}_{1}$ of $80 \%$ 
predicted. Never smokers with normal ventilatory lung function as defined above made up the second control group.

Subjects with diseases or medical treatments known or thought to influence serum Ig levels were not included in the study. Accordingly, the following exclusion criteria were chosen: treatment with $\mathrm{N}$-acetylcysteine, antihistamines or antibiotics; vaccination or other immunomodulating treatment during the 4 weeks prior to the investigation; glucocorticosteroid treatment (oestrogen included), whether local or systemic, or other immunosuppressant treatment during the 2 months before the investigation; and symptoms of infectious disease with pyrexia during the 4 weeks prior to the investigation. In addition, subjects were excluded from the study if they had a post-bronchodilator increase in of $\mathrm{FEV}_{1}>15 \%$ predicted; an abnormal chest radiograph (CB group only); known other active pulmonary diseases such as sarcoidosis, cystic fibrosis, $\alpha_{1}$-antitrypsin deficiency, a history of asthma, allergy or atopy, known immunodeficiency, or other concurrent severe diseases.

CLINICAL EXAMINATION AND PERFORMANCE Following an interview to ensure that all inclusion criteria were fulfilled, ventilatory lung function $\left(\mathrm{FEV}_{1} \%\right.$ predicted) was measured with a Vitalograph Alpha (Vitalograph Ltd, Buckingham, UK) in a standardised manner. ${ }^{11}$ In subjects with $\mathrm{CB}$ a chest radiograph was also taken.

All subjects provided a $10 \mathrm{ml}$ venous blood sample and serum was obtained by low speed centrifugation, frozen, and stored at $-70^{\circ} \mathrm{C}$ awaiting further analysis. All blood samples were taken between 08.00 and 10.00 hours.

\section{SMOKING STATUS}

Systemic exposure to tobacco products was assessed by an enzyme linked immunosorbent assay (ELISA) for cotinine, a metabolite of nicotine which can be measured in serum. A commercially available ELISA kit was used according to the instructions of the manufacturer (STC Technologies Inc, Bethlehem, PA, USA). The qualitative cut off for a positive (cotinine containing) sample with this kit was $25 \mathrm{ng} / \mathrm{ml}$. Subjects with serum concentrations greater than this were considered to have evidence of recent exposure to tobacco products. This was required for inclusion in the smoking groups while all never smokers had to have a negative test for cotinine.

ASSAY OF SERUM IMMUNOGLOBULINS

The content of $\operatorname{IgG}, \operatorname{IgM}$, and $\operatorname{IgA}$ as well as IgG subclasses in serum was assessed by radial immunodiffusion using class specific polyclonal rabbit anti-human $\operatorname{IgG}, \operatorname{Ig} M$, and $\operatorname{IgA}$ (Dakopatts a/s, Glostrup, Denmark) and mouse anti-human monoclonal subclass specific antibodies to IgG1, IgG2, IgG3, and IgG4 (Oxoid Unipath Ltd, Hampshire, UK). The concentration of the immunoglobulin classes and subclasses was expressed in $\mathrm{g} / \mathrm{l}$ and compared with a standard. For the definition of Ig class and IgG subclass deficiency the class reference ranges of the department of clinical immunology (IgG 7.6-22.1 g/1, IgM 0.5-3.4 g/ 1 , and $\operatorname{IgA} \quad 0.2-2.8 \mathrm{~g} / \mathrm{l}$ ) and the IgG subclass reference ranges published by Oxelius ${ }^{12}$ (IgG1 $4.22-12.92 \mathrm{~g} / 1, \quad$ IgG $21.17-7.47 \mathrm{~g} / 1, \quad$ IgG3 $0.41-1.29 \mathrm{~g} / 1$ and $\mathrm{IgG} 4<2.91 \mathrm{~g} / \mathrm{l}$ ) were used. The laboratory is accredited by the Swedish Board for Accreditation and Conformity Assessment (SWEDAC).

An alternative definition of $\mathrm{Ig}$ class and $\mathrm{IgG}$ subclass deficiency was also employed based on the lowest values of the control group of never smokers in the present study (IgG $<6.9 \mathrm{~g} / 1, \quad$ IgM $<0.3 \mathrm{~g} / 1, \quad$ IgA $<0.9 \mathrm{~g} / 1, \quad$ IgG 1 $<3.36 \mathrm{~g} / 1, \mathrm{IgG} 2<1.74 \mathrm{~g} / 1, \mathrm{IgG} 3<0.19 \mathrm{~g} / \mathrm{l}$, and $\mathrm{IgG} 4<0.09 \mathrm{~g} / \mathrm{l})$.

DATA ANALYSIS

A statview 4.5 (Abacus Concepts, Berkeley, CA, USA) software package was used for the statistical analysis. Since most data did not show a normal distribution, data are presented as median values and ranges unless otherwise stated. For comparisons between groups of demographic data, non-parametric methods were used. The Kruskal-Wallis or MannWhitney U tests were performed for quantitative data. The $\chi^{2}$ test with continuity correction according to Yates ${ }^{13}$ or Fisher's exact test was used for comparison of proportions. Immunoglobulin data showed an approximate log normal distribution and were consequently log transformed in order to achieve approximate normal distributions. These log transformed data were then analysed by one way (comparison of study groups) or two way (influence of smoking and sex) ANOVA followed by multiple comparisons according to Tukey-Kramer ${ }^{14}$ and to Scheffe, ${ }^{15}$ respectively, and $95 \%$ confidence intervals (CI) for differences between means (one way ANOVA) and differences of differences of means (two way ANOVA) of log transformed data were constructed. By applying the exponential transformation on these $95 \%$ confidence limits the $95 \%$ CI for the ratio of median values (one way ANOVA) and ratio of ratios of median values (two way ANOVA) were obtained. All tests were two tailed and $\mathrm{p}$ values of $<0.05$ were considered significant. A Spearman rank correlation coefficient was calculated to analyse correlations between quantitative clinical variables.

\section{Results}

SUBJECT CHARACTERISTICS

A total of 100 white subjects (43 never smokers, 24 asymptomatic smokers, and 33 with CB) were included in the study. The demographic and clinical data of the study population are summarised in table 1 . The age distribution was comparable between the groups. Women were over-represented in the CB group compared with the other two groups. The asymptomatic smokers differed from the CB group with a significantly lower number of pack years and cigarettes smoked per day. Ventilatory lung function was significantly lower in the CB group than in the never smokers and the asymptomatic smokers. In the CB group 11 of the 33 subjects (33\%) had mild to moderate 
Table 1 Demographic and clinical data

\begin{tabular}{|c|c|c|c|}
\hline & $\begin{array}{l}\text { Healthy never } \\
\text { smokers (NS) }\end{array}$ & $\begin{array}{l}\text { Asymptomatic } \\
\text { smokers (AS) }\end{array}$ & $\begin{array}{l}\text { Chronic bronchitis } \\
\text { (CB) and recurrent } \\
\text { exacerbations }\end{array}$ \\
\hline $\mathrm{n}$ & 43 & 24 & 33 \\
\hline Age (years) & $53(32-73)$ & $49(34-64)$ & $50(37-68)$ \\
\hline $\mathrm{FEV}_{1}$ (\% pred) & $103(81-133)^{a}$ & $99(83-129)^{\mathrm{b}}$ & $86(63-111)^{a, b}$ \\
\hline Pack years & 0 & $27(11-70)^{\mathrm{c}}$ & $36(13-82)^{\mathrm{c}}$ \\
\hline \multicolumn{4}{|l|}{ Current smoking } \\
\hline (cigarettes/day) & 0 & $15(10-35)^{\mathrm{c}}$ & $20(10-40)^{\mathrm{c}}$ \\
\hline Duration of smoking (years) & 0 & $34(22-49)$ & $34(23-54)$ \\
\hline Duration of CB (years) & 0 & 0 & $10(3-40)$ \\
\hline No of exacerbations in $2 \mathrm{yrs}$ & 0 & 0 & $6(4-20)$ \\
\hline Male/female & $17 / 26$ & $11 / 13$ & $9 / 24$ \\
\hline
\end{tabular}

Data are presented as median values with range in parentheses.

$\mathrm{FEV}_{1}=$ forced expiratory volume in one second.

${ }^{\mathrm{a}} \mathrm{NS} v \mathrm{CB}, \mathrm{p}<0.001$ ' $^{\mathrm{b}} \mathrm{AS} v \mathrm{CB}, \mathrm{p}<0.001 ;^{\mathrm{c}} \mathrm{AS} v \mathrm{CB}, \mathrm{p}<0.01$.

Table 2 Serum levels of immunoglobulins (Ig) in healthy never smokers, asymptomatic smokers, and patients with chronic bronchitis and recurrent exacerbations

\begin{tabular}{llll}
\hline & $\begin{array}{l}\text { Healthy never } \\
\text { smokers }(N S)\end{array}$ & $\begin{array}{l}\text { Asymptomatic } \\
\text { smokers }(A S)\end{array}$ & $\begin{array}{l}\text { Chronic bronchitis }(C B) \\
\text { and recurrent exacerbations }\end{array}$ \\
\hline $\mathrm{n}$ & 43 & 24 & 33 \\
$\mathrm{IgG} \mathrm{(g/1)}$ & $12.0(6.9-18.5)^{\mathrm{a}, \mathrm{b}}$ & $9.9(6.1-12.1)^{\mathrm{a}}$ & $9.7(5.6-15.2)^{\mathrm{b}}$ \\
$\mathrm{IgA}(\mathrm{g} / \mathrm{l})$ & $2.6(0.9-4.5)$ & $1.9(1.0-6.4)$ & $2.0(0.8-4.0)$ \\
$\mathrm{IgM}(\mathrm{g} / \mathrm{l})$ & $1.3(0.3-4.4)$ & $1.6(0.6-3.6)$ & $1.7(0.6-4.0)$ \\
$\mathrm{IgG1}(\mathrm{g} / \mathrm{l})$ & $6.5(3.4-14.2)$ & $6.4(3.5-9.8)$ & $6.6(3.9-11.2)$ \\
$\mathrm{IgG} 2(\mathrm{~g} / \mathrm{l})$ & $4.0(1.7-10.2)^{\mathrm{a}, \mathrm{b}}$ & $2.5(1.0-6.3)^{\mathrm{a}}$ & $2.8(0.9-5.9)^{\mathrm{b}}$ \\
$\mathrm{IgG3}(\mathrm{g} / \mathrm{l})$ & $0.7(0.2-2.9)$ & $0.6(0.2-1.4)$ & $0.8(0.2-1.7)$ \\
$\mathrm{IgG} 4(\mathrm{~g} / \mathrm{l})$ & $0.4(0.1-1.0)^{\mathrm{c}}$ & $0.4(0.1-0.8)$ & $0.1(0.0-1.1)^{\mathrm{c}}$ \\
\hline
\end{tabular}

Data are presented as median values with range in parentheses.

${ }^{a} \mathrm{NS} v \mathrm{AS}, \mathrm{p}<0.001$; $^{\mathrm{D}} \mathrm{NS} v \mathrm{CB}, \mathrm{p}<0.001$; $^{\mathrm{N} S} v \mathrm{CB}, \mathrm{p}<0.01$.

chronic airflow obstruction (median $\mathrm{FEV}_{1} 74 \%$ predicted; range 63-79). This subgroup of subjects with chronic obstructive pulmonary disease (COPD) were on average older (median age $60 v 48$ years) but did not otherwise differ significantly in demographic or clinical variables from the 22 subjects with nonobstructive disease within the CB group (data not shown).

SERUM IMMUNOGLOBULINS AND CHRONIC BRONCHITIS

The results of the serum Ig analyses are presented in table 2. Serum levels of IgG and IgG2 were significantly lower in both asymptomatic smokers and those with CB than in never smokers. The estimated ratio of median values between patients with $\mathrm{CB}$ and never smokers was 0.78 (95\% CI 0.69 to 0.89 ) for IgG and 0.65 (95\% CI 0.50 to 0.83 ) for IgG2. The corresponding ratios between the asymptomatic smokers and non-smokers were 0.79 (95\% CI 0.69 to 0.91 ) and 0.60 (95\% CI 0.50 to 0.83 ), respectively. In addition, serum levels of IgG4 were significantly lower in the CB group than in the non-smokers $(95 \% \mathrm{CI}$ for the ratio 0.39 to 0.88 ). In asymptomatic smokers IgG4 levels were also lower than in non-smokers and almost reached statistical significance $(95 \%$ CI 0.38 to 1.00$)$. IgA and IgG1 levels were lower in both smoking groups than in non-smokers but the differences were not significant. As illustrated in fig 1, most of the difference in IgG levels between the two smoking groups and the non-smokers was due to lower IgG2 levels in the smoking groups.

There were no significant differences for any of the Ig classes or IgG subclasses between patients with $\mathrm{CB}$ and the asymptomatic smokers. In addition, the subgroup of patients with COPD did not differ significantly from the
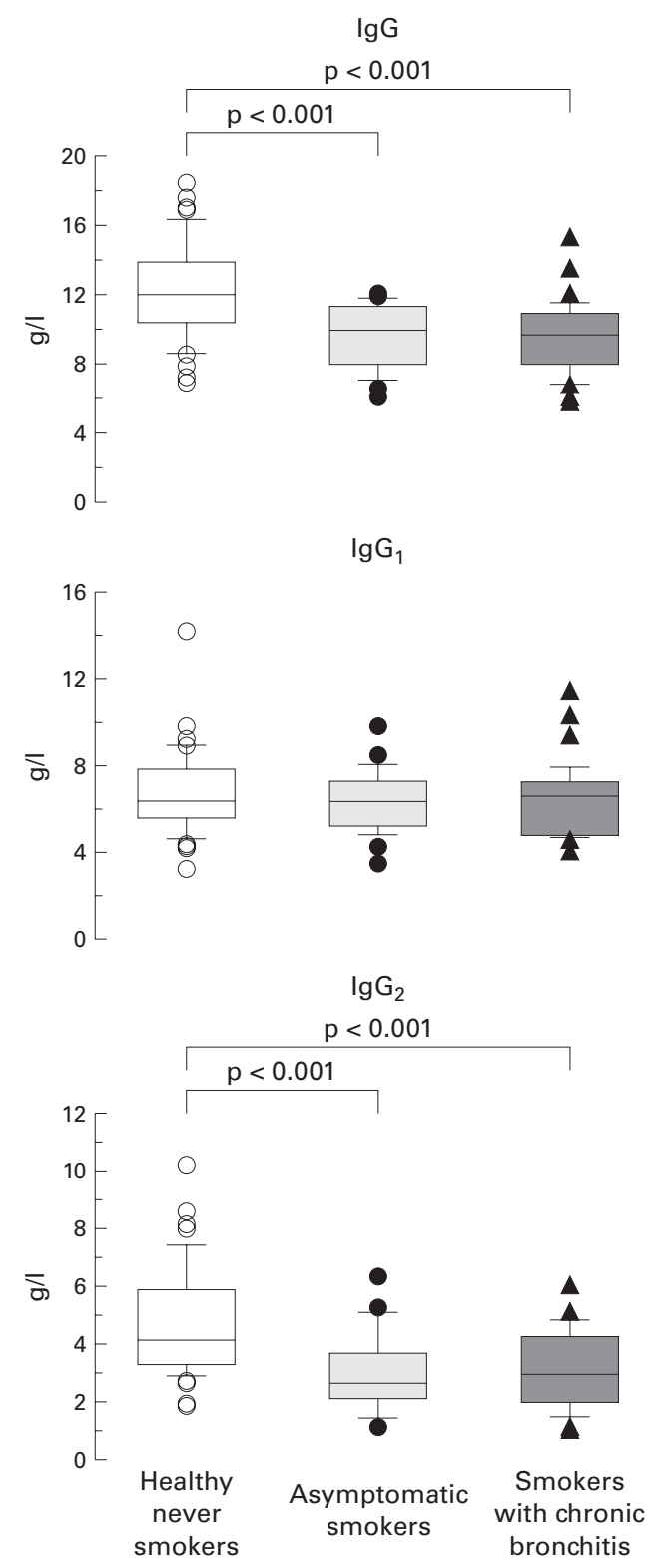

Figure 1 Serum levels of immunoglobulin (Ig) $G, \operatorname{Ig} G 1$ and IgG2 in healthy never smokers $(n=43)$, asymptomatic smokers $(n=24)$, and smokers with chronic bronchitis and recurrent exacerbations $(n=33)$. The $10 \mathrm{th}, 25 \mathrm{th}, 50 \mathrm{th}$, 75 th, 90th percentiles and extreme values are shown.

non-obstructive patients within the CB group with respect to any of the Ig isotypes or IgG subclasses (data not shown).

Eight $(19 \%)$ of the 43 non-smokers were deficient in total IgG or in one or more of the IgG subclasses using the classification of Oxelius. ${ }^{12}$ The corresponding figures in the patients with CB and the asymptomatic smokers were eight of $33(24 \%)$ and 10 of $24(42 \%)$, respectively. These differences were not statistically significant. The numbers of subjects in the three study groups with Ig class and IgG1-3 subclass deficiencies according to Oxelius ${ }^{12}$ are shown in table 3 . The most common IgG subclass deficiency was IgG3. For all subclasses except IgG3, deficient subjects were more numerous in both smoking groups but the numbers were small. There were no subjects with IgA deficiency. Two non-smokers 
Table 3 Number of subjects with immunoglobulin deficiency according to Oxelius ${ }^{12}$ and using an alternative definition based on lower extreme values in never smokers in the present study

\begin{tabular}{|c|c|c|c|c|c|}
\hline \multirow{2}{*}{$\begin{array}{l}\text { Immunoglobulin } \\
\text { deficiency }\end{array}$} & \multirow{2}{*}{$\begin{array}{l}\text { Healthy never } \\
\text { smokers }(n=43) \\
\text { Oxelius }\end{array}$} & \multicolumn{2}{|c|}{$\begin{array}{l}\text { Asymptomatic smokers } \\
(n=24)\end{array}$} & \multicolumn{2}{|c|}{$\begin{array}{l}\text { Chronic bronchitis and } \\
\text { recurrent exacerbations } \\
(n=33)\end{array}$} \\
\hline & & Oxelius & Alternative & Oxelius & Alternative \\
\hline $\operatorname{IgG}$ & 2 & 4 & 2 & 6 & 2 \\
\hline Isolated IgGSCD & 7 & 7 & 4 & 5 & 8 \\
\hline IgG1 & 1 & 2 & 0 & 1 & 0 \\
\hline IgG2 & 0 & 1 & 4 & 2 & 4 \\
\hline IgG3 & 6 & 4 & 0 & 2 & 0 \\
\hline IgG4 & - & - & 0 & - & 4 \\
\hline Multiple IgGSCD & 0 & 1 & 1 & 1 & 2 \\
\hline $\operatorname{IgM}$ & 2 & 0 & 0 & 0 & 0 \\
\hline IgA & 0 & 0 & 0 & 0 & 2 \\
\hline
\end{tabular}

IgGSCD = IgG subclass deficiency.

had $\operatorname{IgM}$ values slightly below the lower limit, in both cases $0.3 \mathrm{~g} / 1$.

Use of the alternative definition of deficiency, based on the lower extreme values in the non-smokers, resulted in lower limits for deficiency in all Ig classes and subclasses with the exception of IgA and IgG2. A comparable number of subjects in both smoking groups had deficiencies in IgG or IgG subclasses using this definition, but IgG2, not IgG3, was the most common IgG subclass deficiency occurring in six of $33(18 \%)$ and five of $24(21 \%)$ in the patients with CB and asymptomatic smokers, respectively.

SERUM IMMUNOGLOBULINS: SMOKING AND SEX To analyse a possible difference between men and women for the effect of smoking on Ig levels, current smokers (those with $\mathrm{CB}$ and asymptomatic smokers) and never smokers of each sex were compared separately. Both IgG and IgG2 were lower in currently smoking men and women than in their never smoking counterparts (data not shown). However, two way ANOVA followed by multiple comparisons revealed an interaction between smoking and sex with a significantly greater difference between smokers and never smokers in women than in men for IgG2. The estimated ratio of ratios of median values was 0.54 (95\% CI 0.32 to 0.90 ). For IgG the interaction was present but was smaller and did not reach statistical significance (0.78 (95\% CI 0.60 to 1.02$)$ ).

CORRELATIONS

We analysed possible correlations between serum levels of IgG2 and (1) age of the total study population, (2) duration of smoking in years, (3) cigarettes per day in current smokers, and (4) number of exacerbations in the past two years in the CB group. No significant covariation between these clinical variables and IgG2 was found.

\section{Discussion}

In the present study the hypothesis of an association between low levels of IgG subclasses or IgG subclass deficiencies and a susceptibility to recurrent exacerbations in patients with $\mathrm{CB}$ was not confirmed. However, current smokers had lower levels of IgG than non-smokers and this was primarily due to lower levels of IgG2. Furthermore, these differences were greater in women than in men, which suggests a greater sensitivity in women to the effects of smoking on serum Ig levels.

Only a few previous studies have focused on serum Ig levels in patients with CB without severe airflow obstruction or bronchiectasis. In most of these studies smoking habits were either not considered ${ }^{16}$ or the composition of the study and control groups made an analysis of changes not related to smoking and sex difficult. ${ }^{8}{ }^{17}$ We previously analysed IgG subclass concentrations in smokers with and without $\mathrm{CB}$ and found a possible connection between low levels of IgG3 and recurrent exacerbations. ${ }^{9}$ This was not confirmed in the present larger study where no significant differences of possible clinical relevance between asymptomatic smokers and smokers with $\mathrm{CB}$ and recurrent exacerbations were found. Judging from this study it would appear that, at least in smokers with $\mathrm{CB}$ and uncomplicated mucosal infections such as recurrent exacerbations, low levels of IgG2 or any other IgG subclass are not important for the increased susceptibility to respiratory infections we see in the clinic.

Deficiency in one or more IgG subclasses, usually $\operatorname{IgG} 2$ or IgG3, and often in conjunction with IgA deficiency, has frequently been found both in patients with chronic mucosal infections such as bronchiectasis and in recurrent sinopulmonary infections. ${ }^{18-20}$ In these studies smoking history and smoking habits are seldom reported. Based on our present results we feel that any conclusions made regarding a connection between IgG subclass deficiency and recurrent respiratory infections in these studies may have been confounded by prevalence of smoking and possibly by sex distribution in the study groups.

The fact that the influence of smoking on IgG2 and hence, to a lesser extent, on total IgG was found to be greater in women than in men has not, to our knowledge, been reported previously. Earlier reports suggesting that smoking may affect IgG2 levels more than the other subclasses have not presented IgG2 levels in men and women separately. ${ }^{21-23}$ Part of the explanation for the sex difference found in our study might be that never smoking women had slightly higher levels of $\operatorname{IgG}$ and $\operatorname{IgG} 2$ than never smoking men, although this was not significant (data not shown). Our findings are in contrast to two other studies where IgG subclass levels were accounted for separately in men and women, ${ }^{24}{ }^{25}$ showing no differences in IgG1 or IgG2 but slightly higher levels of IgG3 in women and of IgG4 in men. However, since the prevalence of smoking in men and women was not reported in these studies, there is at present no good knowledge of sex differences in serum Ig levels in healthy never smokers. The possibility that women are more vulnerable than men to the effect of smoking on serum Ig levels, as indicated by our results, therefore remains an issue to be disproved or confirmed.

The precise mechanism(s) by which smoking affects serum levels of Ig and the component(s) of cigarette smoke responsible for the effect have not been clarified. However, 
evidence of a dose-response relationship, with lower levels of IgG with increased smoking, has been presented. ${ }^{3}{ }^{4}$ We found no dose-response relationship in this study but it must be pointed out that the semiquantitative cotinine ELISA we used only allows determination of two concentration intervals in a positive sample which makes the analysis insensitive. However, the fact that only moderate and heavy smokers were included in our study suggests that much of the effect of smoking is already present in low level smokers and that the relationship between smoking and IgG2 levels is perhaps not of a linear dose-response nature.

A major problem when discussing Ig class and subclass deficiency is the lack of a generally recognised definition of what is meant by "deficient", partly due to the wide range of subclass levels in normal subjects. Several large studies have shown that the frequency distributions of IgG subclasses in healthy adults are skewed, with the possible exception of IgG1, ${ }^{18} 2425$ which was also true in our study (data not shown). It would therefore appear that the use of a normal control range based on the entire range of values in healthy normal individuals, as in several ${ }^{122426}$ but not all ${ }^{202527}$ of the previously published control ranges, is appropriate. The present study shows that it is also important that the influence of smoking, and possibly sex, is taken into account when normal control ranges are considered. We used the most widely quoted control ranges of normal values for IgG subclasses ${ }^{12}$ which is based on 20 healthy subjects with unknown smoking status and male/female ratio. Using this definition, eight of the 24 asymptomatic smokers $(33 \%)$ were deficient in one or more IgG subclasses, making IgG subclass deficiency a very common condition of doubtful clinical relevance in this group. In only one of the previously published studies defining normal control ranges was smoking status accounted for, but its impact on IgG subclasses was not separately reported. ${ }^{26}$ Based on our results, we feel that a control group should not include an unknown number of smokers. Whether normal values should be based solely on healthy non-smokers or whether separate normal values for smokers and non-smokers should be given is debatable. The striking effect of basing normal values only on never smokers is illustrated by our result using the alternative definition of IgG subclass deficiency (table 3). Although about the same fraction of smokers is defined as IgG subclass deficient, the prominent effect of smoking on IgG2 results in a different pattern where fewer individuals have IgG3 deficiency and more have IgG2 deficiency. However, the large number of apparently healthy smokers labelled as IgG subclass deficient strongly supports having separate normal ranges for smokers.

The main conclusion to be drawn from this investigation is that merely altered IgG subclass levels in smokers with CB cannot explain the increased susceptibility for respiratory infections seen in some patients. In addition, our results emphasise the need for new normal ranges for IgG subclasses based solely on never smokers and with possible sex differences taken into account. Moreover, "deficiency" in any Ig class or IgG subclass needs to be redefined to increase its clinical relevance.

The authors would like to thank biostatistician Kjell Pettersson, Department of Statistics, Göteborg University, for skilful assistance with the statistical analysis, and study nurses Ann-Marie Hilmersson and Ing-Marie Dohsé and biotechnician BrittMarie Essman for their excellent work in connection with this study.

Funding: The study received financial support from the Swedish Heart-Lung Foundation and the Göteborg Medical Society.

1 Gulsvik A, Fagerhoi MK. Smoking and immunoglobulin levels. Lancet 1979;i:449.

2 Bridges RB, Chow CK, Rehm SR. Micronutrient status and immune function in smokers. Ann NY Acad Sci 1990;587: 218-31.

3 Mili F, Flanders WD, Boring JR, et al. The association of race, cigarette smoking, and smoking cessation to measures of the immune system in middle-aged men. Clin Immunol Immunopathol 1991;59:187-200.

4 McMillan SA, Douglas JP, Archbold GP, et al. Effect of low to moderate levels of smoking and alcohol consumption on serum immunoglobulin concentrations. F Clin Pathol 1997; 50:819-22.

5 Marcy TW, Merril WW. Cigarette smoking and respiratory tract infection. Clin Chest Med 1987;8:381-91.

6 Fletcher C, Peto R. The natural history of chronic airflow obstruction. BMF 1977;1:1645-8.

7 Boman G, Bäcker U, Larsson S, et al. Oral acetylcysteine reduces exacerbation rate in chronic bronchitis: report of a trial organized by the Swedish Society for Pulmonary Diseases. Eur F Respir Dis 1983;64:405-15.

8 Riise GC, Larsson S, Larsson P, et al. The intrabronchial microbial flora in chronic bronchitis patients: a target for $\mathrm{N}$-acetylcysteine therapy? Eur Respir f 1994;7:94-101.

9 Qvarfordt I, Riise GC, Larsson S, et al. Immunological findings in blood and bronchoalveolar lavage fluid in chronic bronchitis patients with recurrent infectious exacerbations. Eur Respir F 1998;11:46-54.

10 Official Statement of the American Thoracic Society. Standards for the diagnosis and care of patients with chronic obstructive pulmonary disease (COPD) and asthma. Am Rev Respir Dis 1987;136:225-44

11 Quanjer PH, Tammeling GJ, Cotes JE, et al. Lung volumes and forced ventilatory flows. Report of Working Party on Standardization of Lung Function Tests, European Community for Steel and Coal. Official Statement of the European Respiratory Society. Eur Respir F Suppl 1993;16:5-40. pean Respiratory Society. Eur Respir f Suppl 1993;16:5-40.
2 Oxelius V-A. IgG subclass levels in infancy and childhood. Acta Paediatr Scand 1979;68:23-7.

13 Altman DG. Practical statistics for medical research. 1st ed. London: Chapman \& Hall, 1992:235-42.

14 Hochberg Y, Tamhane AC. Multiple comparison procedures. 1 st ed. New York: John Wiley, 1987:91-3.

15 Jerrold HZ. Biostatistical analysis. 2nd ed. Englewood Cliffs: Prentice-Hall, 1984:196-8.

16 Gump DW, Christmas WA, Forsyth BR, et al. Serum and secretory antibodies in patients with chronic bronchitis. Arch Intern Med 1973;132:847-51.

17 Miller RD, Gleich GJ, Offord KP, et al. Immunoglobulin concentrations in serum and nasal secretions in chronic obstructive pulmonary disease. A matched-pair study. $\mathrm{Am}$ Rev Respir Dis 1979;119:229-38.

18 Stanley PJ, Corbo G, Cole PJ. Serum IgG subclasses in chronic and recurrent respiratory infections. Clin Exp chronic and recurrent

19 Popa V, Kim K, Heiner DC. IgG deficiency in adults with recurrent respiratory infections. Ann Allergy 1993;70:41824

20 de Gracia J, Rodrigo MJ, Morell F, et al. IgG subclass deficiencies associated with bronchiectasis. Am $\mathcal{F}$ Respir Crit Care Med 1996;153:650-5.

21 Mattsby-Baltzer I, Edebo L, Järvholm B, et al. Subclass distribution of IgG and IgA antibody response to Pseudomonas pseudoalcaligenes in humans exposed to infected metalworking fluid. F Allergy Clin Immunol 1990;86:231-8.

22 Quinn SM, Zhang JB, Gunsolley JC, et al. Influence of smoking and race on immunoglobulin G subclass concentrations in early-onset periodontitis patients. Infect Immun 1996;64:2500-5.

23 Gunsolley JC, Pandey JP, Quinn SM, et al. The effect of race, smoking and immunoglobulin allotypes on IgG subclass concentrations. F Periodontal Res 1997;32:381-7.

24 French MAH, Harrison G. Serum IgG subclass concentrations in healthy adults: a study using monoclonal antisera. Clin Exp Immunol 1984;56:473-5.

25 Plebani A, Ugazio AG, Avanzini MA, et al. Serum IgG subclass concentrations in healthy subjects at different age: age normal percentile charts. Eur F Pediatr 1989;149:164-7.

26 Hill SL, Mitchell JL, Burnett D, et al. IgG subclasses in the serum and sputum from patients with bronchiectasis. Tho$\operatorname{rax} 1998 ; 53: 463-8$.

27 Schur PH. IgG subclasses: a review. Ann Allergy 1988;58: 